University of Nebraska - Lincoln

DigitalCommons@University of Nebraska - Lincoln

Civil Engineering Faculty Publications

Civil Engineering

2007

\title{
Limitations of Simultaneous Gap-Out Logic
}

Anuj Sharma

University of Nebraska - Lincoln, anujs@iastate.edu

Darcy M. Bullock

Purdue University

Srinivas Peeta

Purdue University

Follow this and additional works at: https://digitalcommons.unl.edu/civilengfacpub

Part of the Civil Engineering Commons

Sharma, Anuj; Bullock, Darcy M.; and Peeta, Srinivas, "Limitations of Simultaneous Gap-Out Logic" (2007). Civil Engineering Faculty Publications. 19.

https://digitalcommons.unl.edu/civilengfacpub/19

This Article is brought to you for free and open access by the Civil Engineering at DigitalCommons@University of Nebraska - Lincoln. It has been accepted for inclusion in Civil Engineering Faculty Publications by an authorized administrator of DigitalCommons@University of Nebraska - Lincoln. 
Published in Transportation Research Record: Journal of the Transportation Research Board of the National Academies, no. 1978 (2006): 42-48. Copyright 2006, Transportation Research Board of the National Academies. Used by permission.

\title{
Limitations of Simultaneous Gap-Out Logic
}

\author{
Anuj Sharma ${ }^{1}$, Darcy M. Bullock ${ }^{2}$ and Srinivas Peeta ${ }^{2}$ \\ ${ }^{1}$ Department of Civil Engineering, University of Nebraska-Lincoln, Lincoln, NE; asharma3@unl.edu \\ ${ }^{2}$ School of Civil Engineering, Purdue University, West Lafayette, IN
}

The current practice of specifying simultaneous gap-out logic places constraints on signal controller logic. These constraints cannot be achieved under high traffic flow conditions, and degraded signal efficiency and dilemma zone protection often result. This study documents the phenomenon described above with set-back detectors at an instrumented intersection in Noblesville, Indiana, and characterizes the problem of dilemma zone protection as being traffic-volume dependent, a factor that should be carefully considered before the simultaneous gap-out logic is applied. Implementation of simultaneous gap-out logic led to max out ranging from $3.5 \%$ to $40 \%$ of cycles per hour during peak traffic flow periods and about 200 dilemma zone incursions per day. Results also indicate that simultaneous gap-out logic performs inefficiently and unsafely under high-volume conditions, whereas its performance is satisfactory under low-volume conditions. Analysis suggests an upper bound on potential savings of about $400 \mathrm{~s}$ of green time per day and a $25 \%$ reduction in dilemma zone incursions.

Intersection crashes constitute a significant portion of total fatalities nationwide; they account for an average of 9,000 fatalities and 1.5 million injuries annually. Red light running (RLR) is a major cause of fatal and injury-related crashes. Also, motorists are more likely to be injured in such crashes. The National Highway Traffic Safety Administration reported that in 2002 there were 921 fatalities and 178,000 injuries resulting from 207,000 crashes attributable to motorists running red lights at signalized intersections. A survey conducted by the U.S. Department of Transportation and the American Trauma Society indicates that $63 \%$ of Americans witness an RLR incident more than once a week and that one in three Americans knows someone who has been injured or killed because of a red light runner.

Rural high-speed isolated intersections are more susceptible to such crashes. Drivers travel at high speeds at such intersections with a high expectancy of proceeding through them without stopping. This expectancy is violated under dilemma zone incursions; this leads to an elevated risk of crashes. The most commonly implemented strategy to eliminate this problem is enabling simultaneous gap-out logic.

Simultaneous gap-out logic is adopted at isolated intersections to provide dilemma zone protection for drivers on the primary street. This logic is widely believed always to provide dilemma zone protection at an intersection. Despite the widespread application of this logic, little, if anything, in the literature reports the limitations of simultaneous gap-out logic in providing dilemma zone protection. This paper provides a framework to evaluate the real-time performance of the simultaneous gap-out logic and highlights its limitations using an instrumented intersection in Noblesville, Indiana.

PROBLEM DESCRIPTION

Dilemma Zone
The dilemma zone constitutes the area on the roadway in which the driver is indecisive about whether to stop or to go on the onset of the yellow interval (1). Figure 1 shows this concept graphically. Driver 1 in the "can go" zone can safely cross the intersection while staying within the speed limit. Driver 3 in "can stop" can come to a safe stop before the stop bar with a comfortable deceleration. Driver 2 in the "dilemma zone" can neither cross the intersection before the onset of red if she stays within the speed limit nor stop the vehicle by applying a comfortable deceleration. Sheffi and Mahmassani (2) identify the dilemma as the driver's decision to proceed through the intersection or to stop when the signal indication changes from green to amber. The concept of a dilemma zone appeared in studies by Gazis et al. (3), Olson and Rothery (4), Crawford (5), and Herman (6). Sheffi and Mahmassani (2) further defined it as that zone within which the driver could neither come to a stop nor proceed through the intersection before the end of the amber phase. Zegeer (7) proposed a probabilistic approach by defining a dilemma zone as the road segment in which more than $10 \%$ and less than $90 \%$ of drivers would choose to stop. Sheffi and Mahmassani (2) developed dilemma zone curves of "percent drivers stopping" versus "distance from stop bar" at the instant the signal indication changes from green to amber. The dilemma zone is also referred to as the "option zone" or the "zone of indecision" (8).

Occurrences of a dilemma zone incursion (presence of driver or drivers in the dilemma zone) elevate the risk of crashes. Dilemma zone incursions have also been identified as major causes of RLR and rear-end collisions. Dilemma zone protection is provided to minimize, and if possible eliminate, the occurrences of dilemma zone incursions. This is usually accomplished by an advance vehicle detector being placed just beyond the start of the dilemma zone (as shown in Figure 1). This detector detects a vehicle and extends the green sufficiently to allow It to travel past the dilemma zone to the "can go" zone. This measure is referred to as a green extension system. Zegeer and Deen (9) conducted a "before-and-after" evaluation of the extension system on three intersections in Kentucky to determine their effect on crashes. Results showed a 54\% reduction in accidents per year at the three sites combined. The duration of the before period was 8.5 years, and the duration of the after period was 3.7 years. There were 70 accidents in the before period and 14 accidents in the after period.

The safety benefits are negated in cases in which the phase reaches its maximum green time and arbitrarily terminates (max out). The green extension system usually uses simultaneous gap-out logic to pool the through lanes of high-speed movement. The green extension logic works well at low-volume conditions. However, the frequency of max out increases with the increase in traffic volume and thus jeopardizes both safety and efficiency of operations at the intersection. Enhanced systems including the TTI truck priority system (10) 


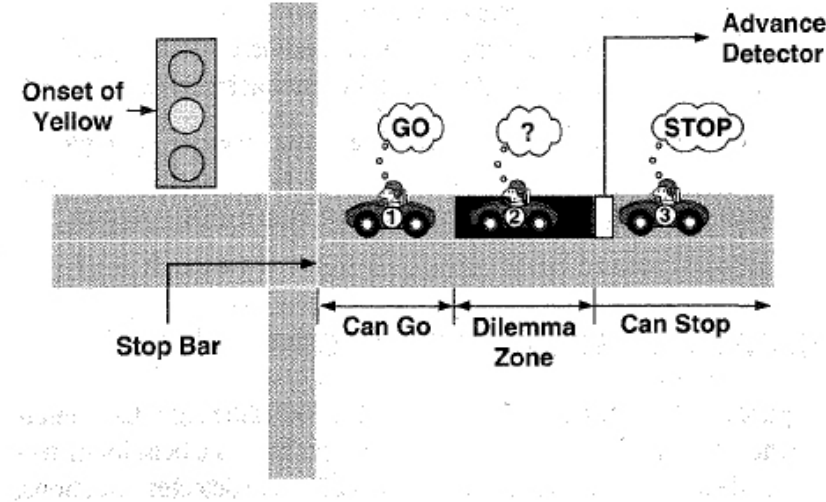

FIGURE 1 Dilemma zone.

and the intelligent detection-control system (11), which promise improved dilemma zone protection, have also been developed but are still not widely used because of high technology cost. Some methodologies $(12,13)$ have been developed that dynamically vary the clearance intervals (yellow clearance and all red) to minimize dilemma zone incursions. These methodologies have not been widely implemented or tested. They can be used to complement the methodologies that extend the green interval for eliminating dilemma zone incursions. This paper focuses on the evaluation of simultaneous gap-out logic, which is the most commonly used feature, available in almost all controllers, for dilemma zone protection. The concept of simultaneous gap-out logic is explained next.

\section{Simultaneous Gap-Out Logic}

In actuated control, Phases 2 and 6 (main-street through phases) are most often linked for gap-out purposes. That imposes an additional constraint on the control system. The constraint requires that when crossing the barrier, Phases 2 and 6 must gap-out together to terminate the green interval. In the absence of simultaneous gap-out logic, if Phase 2 gaps out before Phase 6 both phases go to clearance as soon as a gap is found in Phase 6 regardless of any new call placed on Phase 2. With simultaneous gap-out enabled, the new call will extend Phase 2 even though it would have already gapped out. Here, Phase 2 and Phase 6 need to gap-out simultaneously to end the phases. Hence, the simultaneous gap-out logic inherently increases the likelihood of max out scenarios.

Figure 2 illustrates the principle of simultaneous gap-out logic for a hypothetical intersection. Figure 2a shows the hypothetical intersection with the position of the cars at time zero. Figure $2 \mathrm{~b}$ plots the time at which the advance detectors of northbound and southbound are actuated. The third plot from the top in Figure $2 \mathrm{~b}$ shows the actuations seen by the controller if the simultaneous gap-out logic was implemented. An extension time of $4 \mathrm{~s}$ is assumed (with each actuation, green is extended by $4 \mathrm{~s}$ ). The max out time is assumed to be $18 \mathrm{~s}$. There are three vehicles in the northbound direction passing the advance detector at time $1 \mathrm{~s}, 12 \mathrm{~s}$, and $16 \mathrm{~s}$ and three vehicles in the southbound direction that are detected by the advance detector at time $3 \mathrm{~s}, 5.5 \mathrm{~s}$, and $9 \mathrm{~s}$. Suppose that Phase 2 services the northbound direction and that Phase 6 services the southbound direction. If the simultaneous gap-out logic is not implemented, Phase 2 will gap-out at $5 \mathrm{~s}$ and Phase 6 at $13 \mathrm{~s}$; thus Phases 2 and 6 enter the clearance interval at $13 \mathrm{~s}$. However, as can be observed from Figure 2, one vehicle at $12 \mathrm{~s}$ will be pres

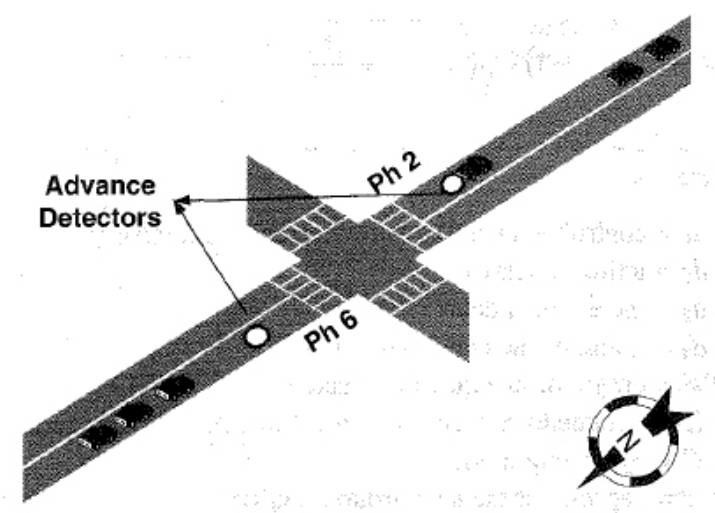

(a)

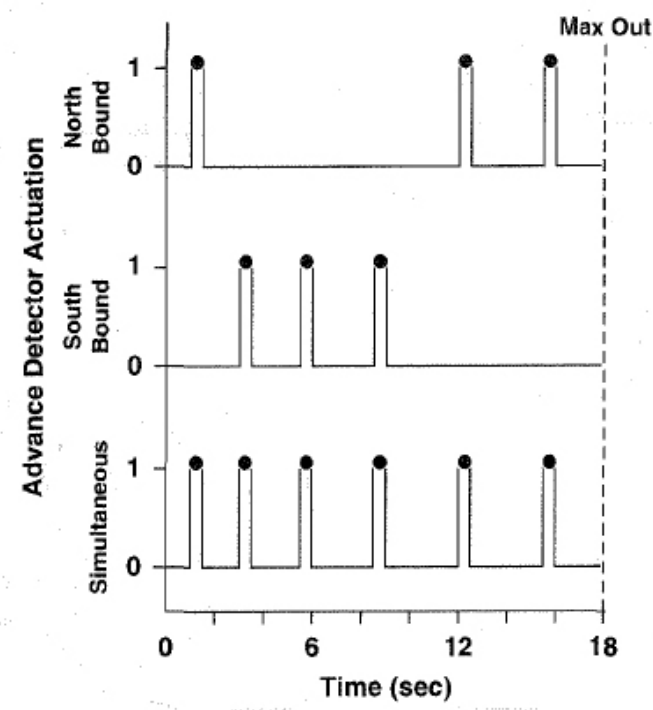

(b)

FIGURE 2 Illustration of simultaneous gap-out logic: (a) example intersection and $(b)$ example detector inputs.

ent in the dilemma zone. If instead, the simultaneous gap-out logic is implemented, Phases 2 and 6 keep extending until $18 \mathrm{~s}$, when the phase goes to the clearance interval as a result of max out. However, this also leads to one dilemma zone incursion. There would be no dilemma zone incursion if the max time were greater than $20 \mathrm{~s}$. But with a max out time setting of $18 \mathrm{~s}$, the simultaneous gap-out logic drags the cycle length without providing any safety benefits.

The example above illustrates that simultaneous gap-out logic can be problematic in cases of medium to high volumes. Under such scenarios, it will reduce the efficiency of the intersection without any dilemma zone protection when the phases max out. The maxing out of phases leads to an increase in cycle lengths. The increase in cycle length results in increased delay in the intersection, thereby increasing the travel time and vehicle operating costs. Highway Capacity Manual (14) delay equations shown below relate the delay at a signalized intersection with the cycle length.

$$
\begin{aligned}
& d=d_{1}(P F)+d_{2}+d_{3} \\
& d_{1}=\frac{0.5 C\left(1-\frac{g}{C}\right)^{2}}{1-\min (1, X) \frac{g}{C}}
\end{aligned}
$$




$$
d_{2}=900 T\left((X-1)+\sqrt{(X-1)^{2}+\frac{8 k I X}{c T}}\right)
$$

where

$d=$ control delay to the through movement (s/veh),

$d_{1}=$ uniform delay (s/veh),

$d_{2}=$ incremental delay (s/veh),

$d_{3}=$ initial queue delay (s/veh),

$P F=$ progression adjustment factor,

$X=$ volume to capacity ratio for the through lane group,

$C=$ cycle length (s),

$c=$ capacity ofthe lane group (veh/h),

$g=$ effective green time for the through lane group (s),
$T=$ duration of analysis period (h),

$k=$ incremental delay adjustment for actuated control, and

$I=$ incremental delay adjustment for filtering by upstream signal.

This paper provides insights for developing adaptive strategies in the future that consider the inverse relation between dilemma zone protection and efficiency at moderate and high traffic volumes.

\section{DATA COLLECTION AND PROCESSING}

Figure 3 shows the data collection site located at the signalized intersection of SR-37 and SR-38 in Noblesville. This is a heavily instrumented intersection with capabilities for collecting detector actuations, signal states, and simultaneous video recording

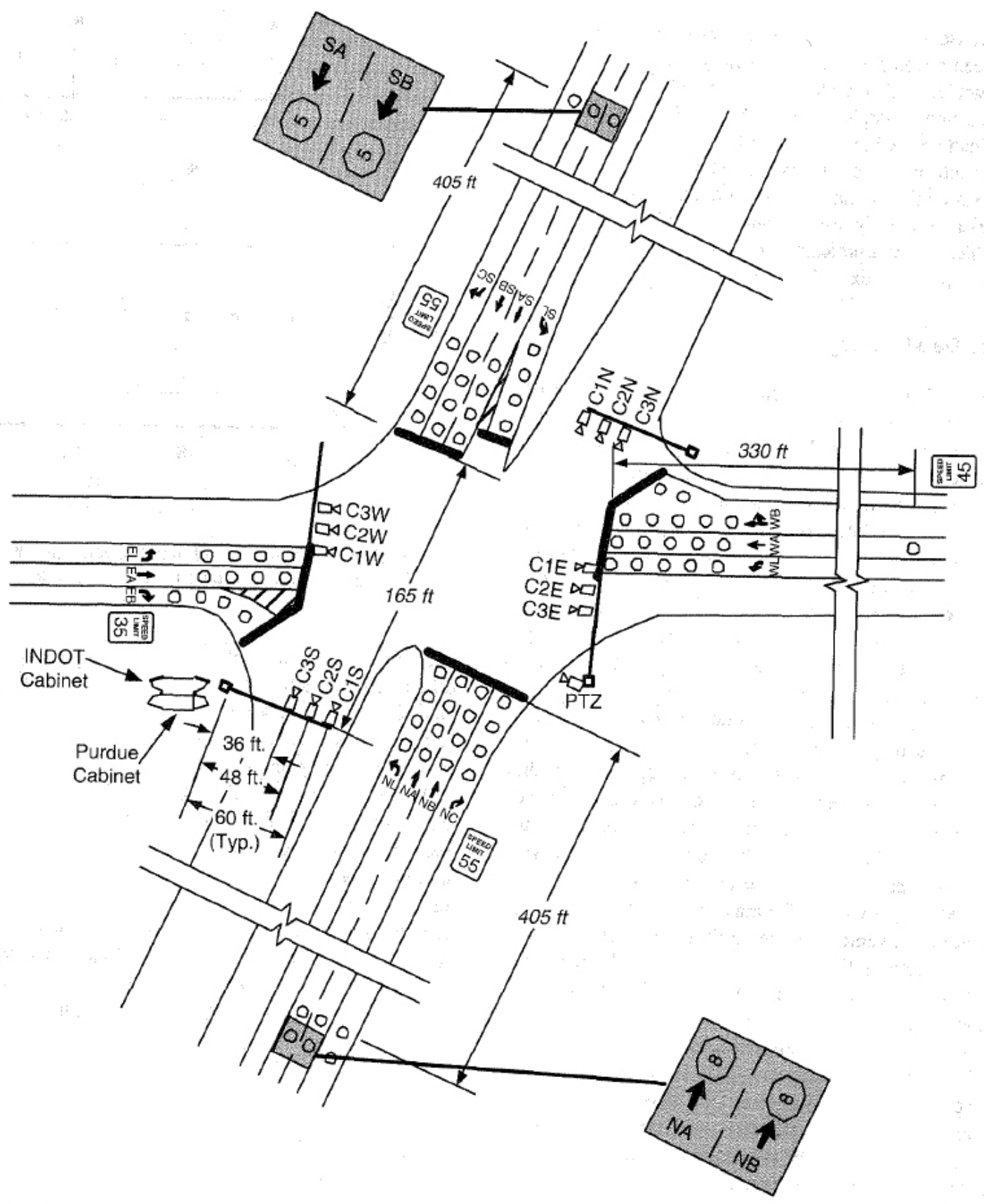

FIGURE 3 Data collection site in Noblesville. 
of theexistingtrafficconditions. Thenorthboundandsouthbound approaches are the high-speed approaches with a posted speed limit of $55 \mathrm{mph}(88 \mathrm{~km} / \mathrm{h})$. These are the approaches of interest.

Detectors NA8, NB8, SA5, and SB5 were used for data collection. These are the set of advance detectors located $405 \mathrm{ft}$ away from the stop bar. Phase data were obtained for Phases 2 and 6 also. Table 1 shows an example data log file. The events are recorded in the data log file in the order in which they occur. It can be seen from Table 1 that at 12:00:05.046 a.m. Phase 6 red turned off (state $=0$ ), that is, Phase 6 turned green. Similarly, there was actuation (state $=1$ ) of Detector NB8 (shown in Figure 3) at 12:00: 18.196 a.m., and it turned off (state $=0$ ) at 12:00:18.396 a.m. The detector actuations and phase changes can be recorded in a data file with a precision of $1 / 1,000$ of a second and with an accuracy to within approximately $1 / 100$ of a second. Data were collected for the 24 -h period on Tuesday between 12:00 a.m. on 05/31/05 and 12:00 a.m. on 06/01/05. Matlab (15) code was used for data processing.

Two signal logic approaches were evaluated on a cycle-bycycle basis. They are labeled the "traditional approach" and the "ideal approach." A maximum green time of $40 \mathrm{~s}$ and a green extension time of $4 \mathrm{~s}$ were used for the evaluation. The green extension of $4 \mathrm{~s}$ was calculated to provide dilemma zone protection for vehicles within the speed range of 35 to $55 \mathrm{mph}$. The traditional approach uses the standard simultaneous gap-out logic. The ideal approach assumes perfect a priori knowledge of the future actuation and tries to avoid max out by reducing the number of detectors (lanes) included in the simultaneous gap-out logic. It provides a benchmark for the upper limit on the potential savings obtainable compared with the traditional approach. Figure 4 compares the traditional and ideal approaches. The ideal approach begins with traditional simultaneous gap-out logic at the start of green. At the end of a prespecified green duration, the simultaneous gap-out strategy constraints are relaxed. Instead, the maximum number of lanes that can avoid max out are included in the simultaneous gapout logic. In ongoing research, the authors are analyzing methods to determine the "optimal" prespecified green duration and the maximum number of lanes for the simultaneous gapout logic considering the inverse relation between dilemma zone protection and efficiency.

\section{Traditional Approach}

The durations of green for Phases 2 and 6 were calculated by using the simultaneous gap-out logic. In the case of max times
TABLE 1 Example of Data Collection at Noblesville, Indiana

\begin{tabular}{llll}
\hline $\begin{array}{l}\text { Detector } \\
\text { Title }\end{array}$ & Date and Time & State & Description \\
\hline PH6 & $5 / 31 / 200512: 00: 05.046$ a.m. & 0 & Phase 6 turns green \\
NB8 & $5 / 31 / 200512: 00: 18.196 \mathrm{a} . \mathrm{m}$. & 1 & Detector NB8 turns on \\
NB8 & $5 / 31 / 200512: 00: 18.396 \mathrm{a} . \mathrm{m}$. & 0 & Detector NB8 turns off \\
PH2 & $5 / 31 / 200512: 00: 33.946 \mathrm{a} . \mathrm{m}$. & 1 & Phase 2 turns red \\
PH6 & $5 / 31 / 200512: 00: 33.946 \mathrm{a} . \mathrm{m}$. & 1 & Phase 6 turns red \\
SB5 & $5 / 31 / 200512: 00: 43.046 \mathrm{a} . \mathrm{m}$. & 1 & Detector SB5 turns on \\
SB5 & $5 / 31 / 200512: 00: 43.392 \mathrm{a} . \mathrm{m}$. & 0 & Detector SB5 turns off \\
NB8 & $5 / 31 / 200512: 00: 44.593 \mathrm{a} . \mathrm{m}$. & 1 & Detector NB8 turns on \\
\hline
\end{tabular}

forcing a phase to terminate, the total number of dilemma zone incursions on all four lanes were reported. The number of dilemma zone incursions was determined by a counting of the number of vehicles that cross the advance detectors in the last 4 $\mathrm{s}$ before the ending of the through green phase.

\section{Ideal Approach}

The ideal approach uses previous knowledge of the future to select a strategy that will, on average, provide maximum dilemma zone protection without triggering max out. For example, if the strategy using all four lanes in the simultaneous gapout logic leads to max out, the ideal approach will test whether a subset of any three lanes can be used in the simultaneous gapout logic and avoid max out. It will use the three lanes that provide the least extension to the phases. However, there are situations in which the queue does not clear in at least one of the four lanes; thus the minimum green cannot be served, and the phase terminates through max out. These situations occur at high volumes, and even the ideal approach will provide no benefits in such instances.

In the field, stochastic control logic would be implemented by a determination of when a phase is likely to max out; then the maximum number of lanes that would avoid the max out would be included. The lanes are chosen to minimize the extension of the green phase.

A separate study was performed to measure the variation of speed during the course of a day. This study was performed to evaluate the effects of congestion reducing the speed and po-

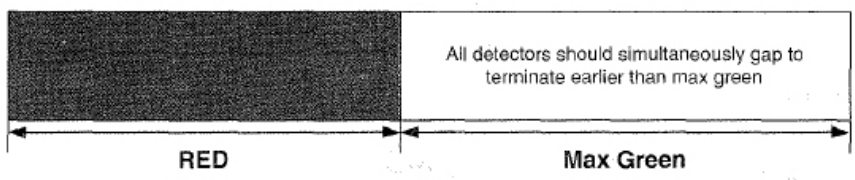

(a)

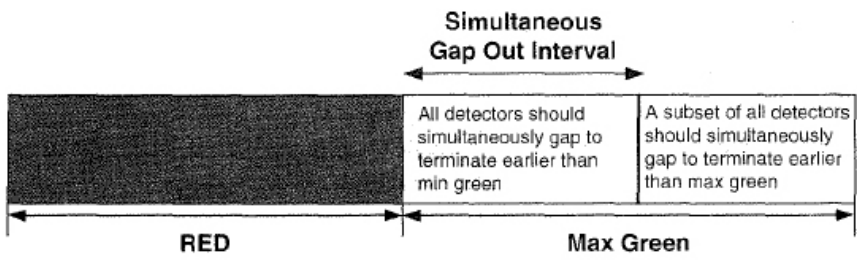

(b)

FIGURE 4 Description of approaches: (a) traditional and $(b)$ ideal. 
tentially negating the need for dilemma zone protection. Figure 5 shows the daily variation of average speed, $85^{\text {th }}$ percentile speed, and $15^{\text {th }}$ percentile speed during the course of a day. The data were collected on Friday 10/21/05. As can be seen from Figure 5, average speed has a modest drop. However, the $85 \%$ speed remains virtually unchanged. This $85 \%$ speed corresponds to the vehicle at the back of the queue most likely to encounter the dilemma zone. Hence, the dilemma zone boundaries do not change significantly during peak hour congestion.

\section{RESULTS}

Figure 6 shows the percentage of cycles maxing out per hour and the number of dilemma zone incursions under the traditional approach. It indicates that the simultaneous gap-out logic works well during the night when traffic volumes are low. However, during the morning, noon, and evening peaks, the percentage of max outs can be substantial and range from $3.5 \%$ to as high as $40 \%$. High percentages of max out are usually observed during the evening peak. The $40 \%$ max out suggests that nearly half of the cycles in that hour were forced to max out. The higher frequency of max outs during the peak periods have a negative impact on the operational efficiency dur- ing those periods because cycle length extensions may lead to excessive delays on the cross streets. Further, as described earlier, max out does necessarily ensure dilemma zone protection.

In the dilemma zone incursion plot of Figure 6, the bars represent the number of incursions occurring per hour and the solid line denotes the cumulative sum of incursions up to that hour. The figure indicates that 213 incursions occurred on the day the data were collected, and the highest hourly rate of incursions was 60 vehicles/h. These numbers are highly significant from a safety standpoint because they indicate the number of drivers exposed to higher risk of crashes per day. These figures are substantial when aggregated across all high-speed rural intersections in the country because they indicate that a significant proportion of the total driver population faces high crash risk each day.

Further, Figure 6 suggests a correlation between cycles maxing out and the number of dilemma zone incursions. That correlation suggests the potential for developing "optimal" signal control strategies that simultaneously reduce the number of max outs and the number of dilemma zone incursions. However, this trend is not universal and indicates the need for stochastic models that explicitly account for the randomness and inverse relationship of these two objectives.

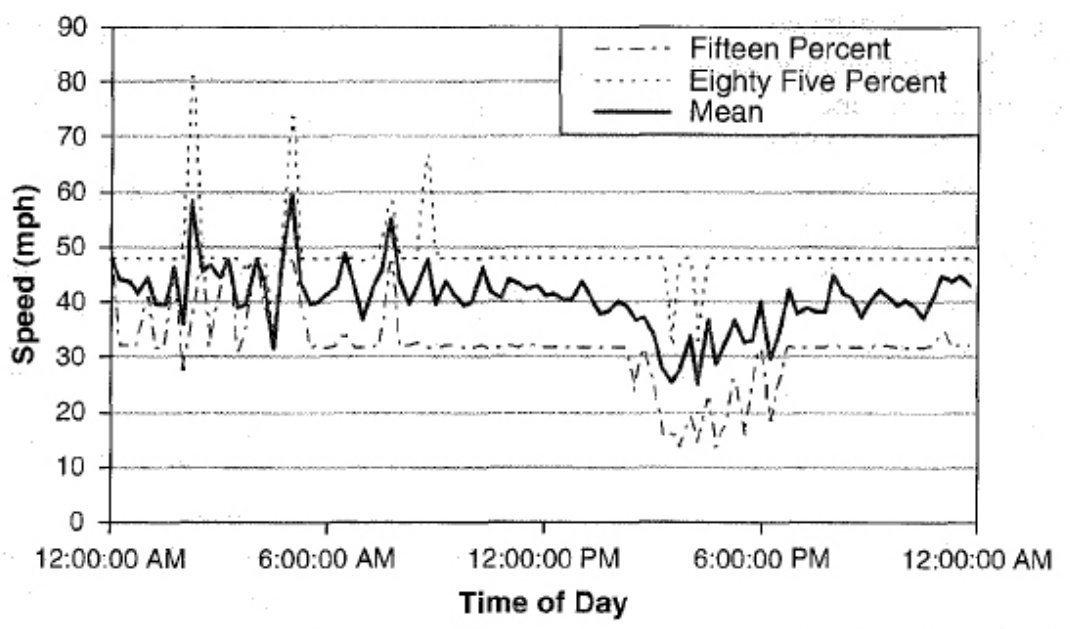

(a)

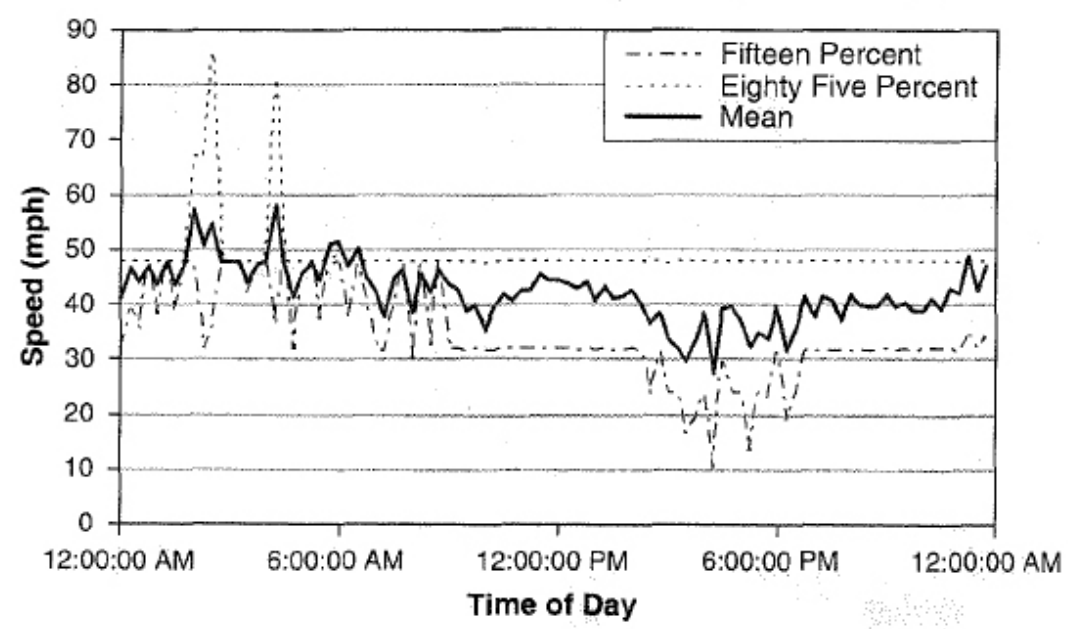

(b)

FIGURE 5 Daily variation in speed in northbound direction at Noblesville: (a) during green in NA lane and $(b)$ during green in NB lane. 


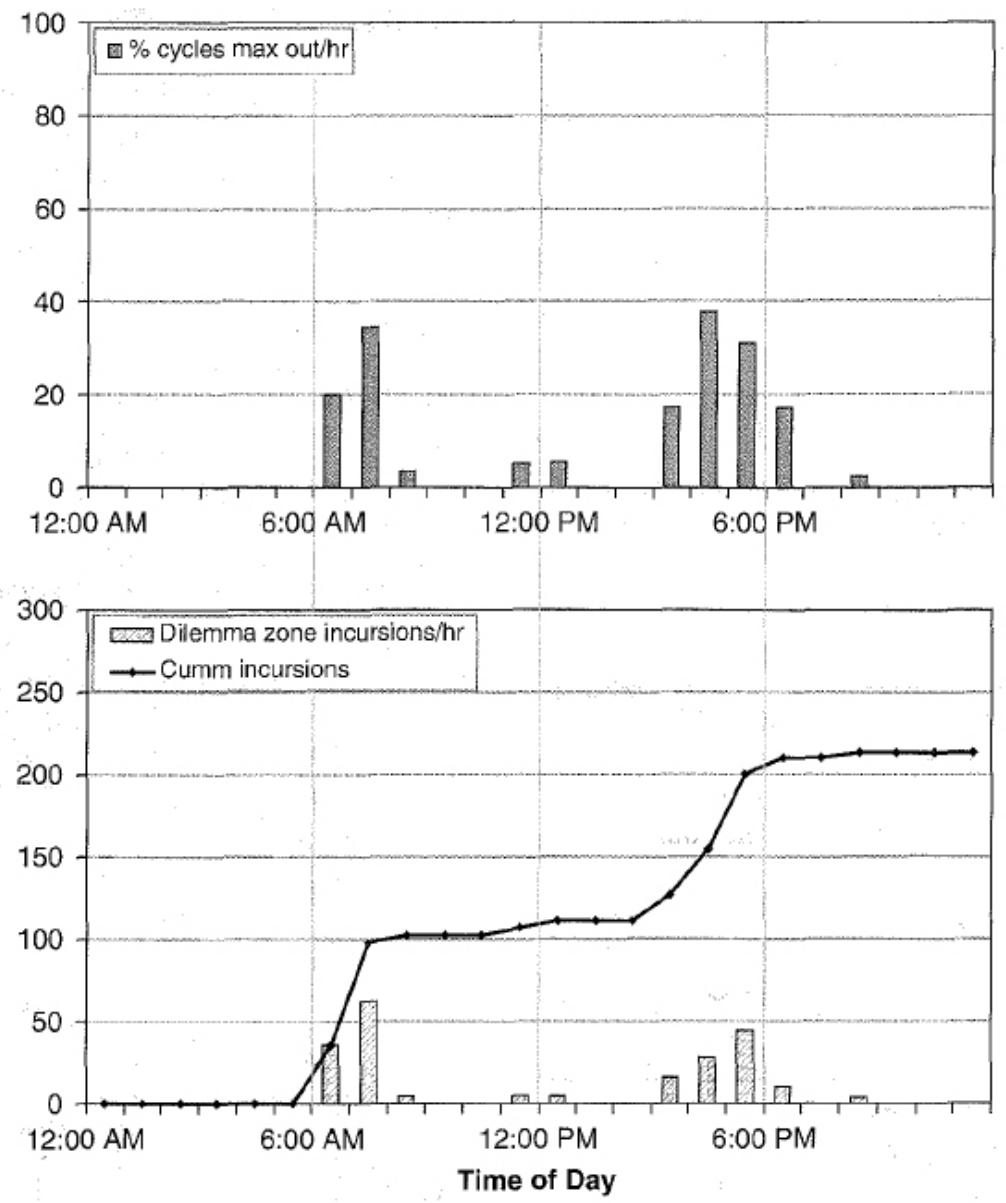

FIGURE 6 Performance of traditional approach on May 31, 2005.

Figure 7 plots the strategies applied in the ideal approach. In many instances, dropping just one of the four lanes (identified by Points a in Figure 7) linked to the simultaneous gap-out logic can prevent the max-out occurrence. However, the figure also illustrates that there are cases (denoted by Points $b$ in the figure) in which dropping all four lanes does not prevent max out because the queues cannot be cleared owing to the heavy traffic. Insights from this figure further reinforce the need for stochastic models that can adapt to real-time data and generate "optimal" strategies to terminate green.

Figure 8 shows potential savings in cycle length reduction as well as reductionin dilemmazoneincursions thatcan beachieved

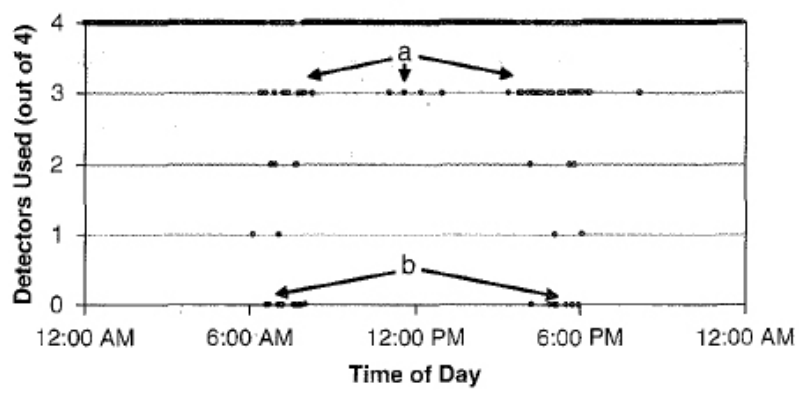

FIGURE 7 Strategy applied on May 31, 2005, assuming perfect knowledge. by applying an inexpensive and simple strategy of using a subset from among the four lanes linked to the simultaneous gapout logic. For academic purposes, to show the potential benefits that can be achieved perfect a priori knowledge ofthe future was assumed. The gross cycle length reductions obtained for the ideal approach were adjusted for the additional time required to serve the excess vehicles (served by traditional approach) that join the queue due to early return to green in the ideal approach. In the study example, about $400 \mathrm{~s}$ of cycle length can be saved. These savings will occur during peak periods of the day, when the intersection has little excess capacity. These savings correspond to increased throughput of approximately 800 vehicles per day during the peak periods (assuming the four lanes can be serviced during the saved green time). Reduced cycle lengths will also lead to reduced delays and queue lengths on the secondary streets, thereby reducing driver frustration on these streets and improving public perception of the efficiency of these signal systems. Figure 8 further illustrates that a reduction of approximately 50 dilemma zone incursions per day could potentially be accomplished with such logic. That corresponds to about a $25 \%$ reduction in dilemma zone incursions per day for this case study. During certain periods the number of dilemma zone incursions might be higher under the ideal approach, but on an average, it will be lower under the traditional approach. As stated earlier, this suggests the need for developing stochastic models to enhance the efficiency and safety objectives more robustly. 


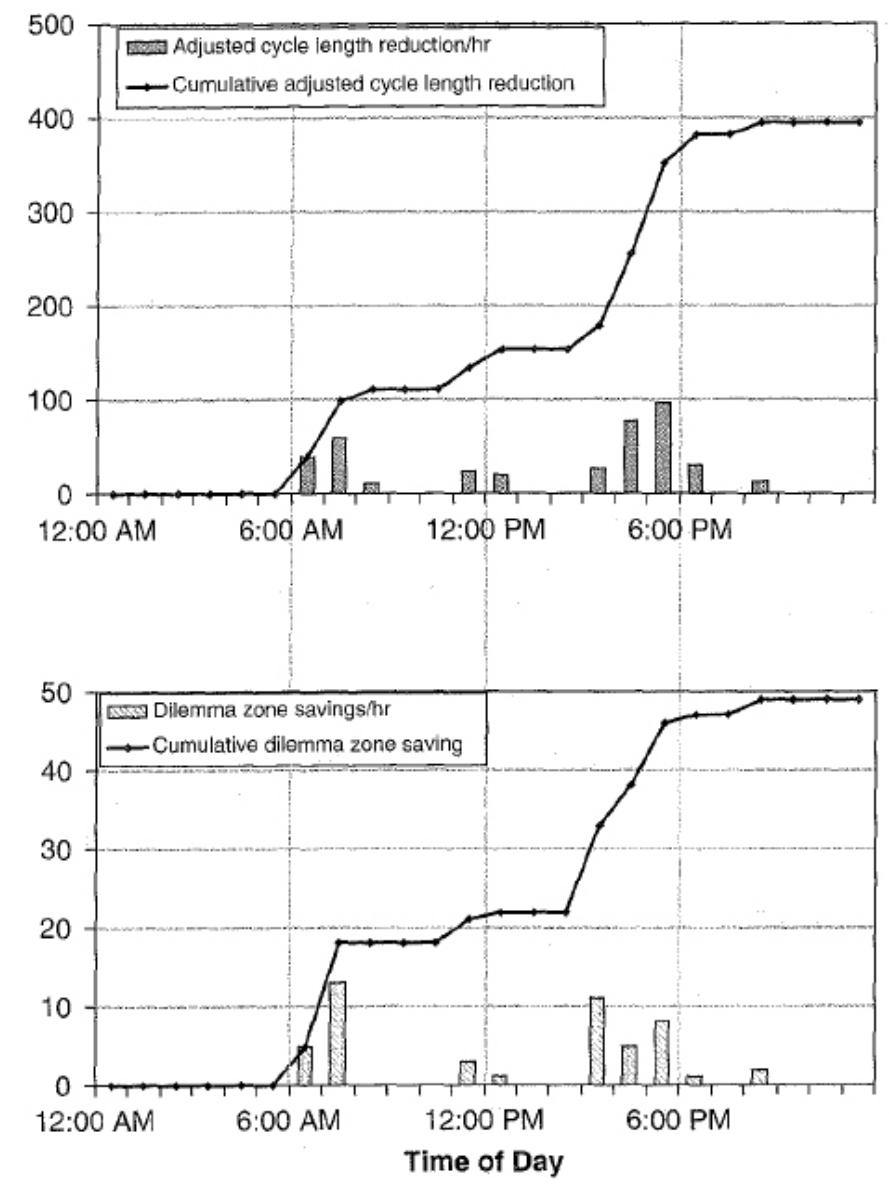

FIGURE 8 Potential savings by applying ideal approach on May 31, 2005.

\section{CONCLUSIONS AND RECOMMENDATIONS}

Simultaneous gap-out logic is widely used in the field with the intent of enhancing safety at the expense of efficiency. The motivation of this paper is to initiate a discussion on the performance of simultaneous, gap-out logic. Study results suggest that the dilemma zone performance deteriorates steeply during peak periods. An important insight is that the frequency of both max outs and dilemma zone interactions increases, on average, during the peak period. So, potential exists for strategies that can improve on one or both of the primary objectives. As a preliminary step, the authors benchmark the perc formance of a simple and inexpensive strategy to enhance the perc formance of simultaneous gap-out logic. Ongoing research seeks to develop stochastic models that adapt to the field data and trade off the efficiency and safety objectives to generate nondominated solutions to this problem.

\section{ACKNOWLEDGMENTS}

This work was supported in part by the National Cooperative Research Program and the Joint Transportation Research Program administered by the Indiana Department of Transportation and Purdue University.

\section{REFERENCES}

1. The Traffic Safety Toolbox: A Primer on Traffic Safety. Institute of Transportation Engineers, Washington, D.C., 1999.

2. Sheffi, Y. and H. A. Mahmassani. Model of Driver Behavior at High Speed Signalized Intersections. Transportation Science, Vol. 15, No.1, 1981, pp. 50-61.

3. Gazis, D., R. Herman and A. Maradudin. The Problem of the Amber Signal Light in Traffic Flow. Operations Research, Vol. 8, No.1, 1960, pp. 112-132.

4. Olson, P. L. and R. W. Rothery. Deceleration Levels and Clearance Times Associated with the Amber Phase of Traffic Signals. Traffic Engineering, Vol. 42, No.4, 1972, pp. 16-19.

5. Crawford, A. Driver Judgment and Error During the Amber Period at Traffic Lights. Ergonomics, Vol. 5, 1962, pp. 513-532.

6. Herman, R. Problem of the Amber Signal Light. Traffic Engineering and Control, Vol. 5, 1963, pp. 298-304.

7. Zegeer, C. Effectiveness of Green-Extension Systems at HighSpeed Intersections. Research Report 472. Kentucky Department of Transportation, Frankfort, 1977.

8. McCoy, P. T. and G. Pesti. Improving Dilemma-Zone Protection of Advance Detection with Advance-Warning Flashers. Transportation Research Record: Journal of the Transportation Research Board, No. 1844, 2003, pp. 11-17.

9. Zegeer, C. V. and R. C. Deen. Green-Extension Systems at High-Speed Intersections. ITE Journal, Nov. 1978.

10. Middleton, D. D. Jasek, H. Charara and D. Moris. Evaluation ofInnovative Methods to Reduce Stops to Trucks at Isolated Signalized Intersections. Report No, TX-97/2972-S. Texas Department of Transportation, Austin, Sept. 1997.

11. Bonneson, J., D. Middleton. K. Zimmerman, H. Charara and M. Abbas. Intelligent Detection-Control Systemfor Rural Signalized Intersections. Report No. FHWA/TX-03/40222. Texas Department of Transportation, Austin, Aug. 2002.

12. Saito. T., N. Ooyama and K. Sigeta. Dilemma and Option Zones, the Problem and Countermeasures-Characteristics of Zones, and a New Strategy of Signal Control for Minimizing Zones. Presented at Road Traffic Control, Third International Conference, London, 1990.

13. Optisoft. Red Light Hold. http://www.optisoft-its.com/ products.cfm?PageID $=39$.

14.Special Report 209: Highway Capacity Manual, 3rded.(1997update).TRB.NationalResearchCouncil,Washington,D.C.,1998.

15. MATLAB 6.5. Mathworks, Inc., Natick, Mass., 2003.

The contents of this paper reflect the views of the authors, who are responsible for the facts and accuracy of data presented here, and do not necessarily reflect official views or policies of the sponsoring organizations, nor do the contents constitute a standard, specification, or regulation.

The Traffic Signal Systems Committee sponsored publication of this paper. 